\title{
Economic Analysis of Wheat Forecasting Analysis and Price Shocks in Wheat Market in Pakistan: A Survey
}

\author{
Professor Dr. Abdul Latif \\ Chairman, Department of Management Sciences, Islamia University Bahawalpur, Pakistan \\ E-mail: drabdullatif@hotmail.com \\ Nadeem Bhatti \\ Head of Faculty, North American College, 730-Yonge Street, Suite No. 207 \\ Toronto, Ontario, M4Y 2B7, Canada \\ Dr. Ghulam Murtaza Maitlo \\ Chairman, Deptt: Of Commerce, Shah Abdul Latif University Khairpur Mirs, Pakistan \\ Muhammad Suhail Nazar \\ Assistant Professor, Department of Management Sciences \\ Islamic University Bahawalpur, Pakistan \\ E-mail: Suhail_nazar@yahoo.com \\ Faiz Muhammad Shaikh \\ Assistant Professor, SZABAC-Dokri-Larkana, Pakistan \\ E-mail: faizanmy2000@hotmail.com
}

Received: June 13, 2011

Accepted: September 13, $2011 \quad$ Published: March 1, 2012

doi:10.5539/ass.v8n3p225

URL: http://dx.doi.org/10.5539/ass.v8n3p225

\begin{abstract}
Pakistani wheat growers and their economic implications are analyzed through alternative specifications of the Demand Model. Existences, nature of production lags, and the choice between expected wheat and gross returns were taken as the preferred explanatory variables of producers' response to the changing economic condition. The analyses indicate that there are lags which are, primarily, due to the difficulties and cost of rapid adjustment rather than to the time required to revise expectations. The statistical results were similar for the alternative specification of gross margins and wheat as the economic decision available. However, the wheat elasticity derived using the gross margins specification were about a third of those using the wheat specification.
\end{abstract}

Keywords: Supply, Response, Wheat, Growers, Rural area

\section{Introduction}

Applied demand analysis is usually taken to refer to the micro economic analysis of consumer and producer behavior, especially the nature of input demand and consumer demand equations. According to Stigler's (1954) survey of earlier research applied demand analysis has a long history going back to the 1970s I England with the budget studies of David Davies and Sir Frederic Morton Eden. Regarding the role of prices I determining consumption. Stigler(1954,p.103) argues that systematic and cumulative work began in the 1870s. The earliest empirical analysis known to Stiger's of the relationship between prices and quantities consumed was carried out in 1861 by Ernst Engel (1857)famous budget study led to what is now known as Engel's law the proportion of income devoted to food declines with increasing income. Engel's 1861 research dealt with harvest and prices of 
ryne in Prussia fro the period of 1846-61. The whole area of the applied demand analysis is no extensive that a comprehensive survey would not be possible within the confines of the single paper. Fortunately number of books on the topic are now available, including Bewley (1986,Deaton, and Muelbeaur (1986), Gold Berger(1987) Philips(1974),Pollack and Wales (1992) Additionally recent major survey articles are Bludell (1988), Blundell et al (1993) and Deaton (1986). The literature is often plagued with claims and counter claims regarding the benefits of one approach over other. For those who do not work in the field and have to rely on the literature for guidance, it is thus often difficult to assess these claims.

Agriculture is the largest sector of Pakistan's economy. The agriculture sector contributes around 21.9 percent in GDP, and engaged half of the total employed labor force. It is largest source of foreign exchange earnings and meets raw material needs' of country's major industries such as textile and sugar production. (Economic Survey of Pakistan (2007-08). The growth in the agriculture sector increased from 4.6 percent to 7.8 percent in the current year. This increase attributes to 9 percent expansion in major crops, 4.9 in minor crops, 5.6 percent in livestock, and 8.3 in fisheries sector. A feature of improved growth in the agriculture sector is record production of wheat and wheat and recovery in cotton (Economic Survey of Pakistan 2007-08).

Improved growth in a agriculture sector is attributed to the government's agricultural policy reforms such as waiving of interest on loans, introduction of Khushali bank, support Wheat policy and introduction of micro credit facility. The growth is also attributed to timely measures to get cotton out of deep-seated crisis (at el S.M.Nasir) Wheat is the second principal food and commercial crop and occupies about $10 \%$ of the total cropped area. The total cropped under the wheat during the year 2007-08 17000thousand hectares, and production was 1966 million tons (Economic survey of Pakistan).

The actual prices and their lag prices may be expressed either in enumerative currency (Rao and Sharma et al, 1999) Thailand, India, Chad are the main competitors of Pakistan (Shaikh et al) The government of Pakistan is taking effective measures to increase the yield, production and quality of export Wheat. Research efforts are continuing on developing high yielding varieties of Wheat. Emphases are also being laid on agronomic research as well as on improved extension services, fertilizer use, direct seedling etc. The flow of input and credits is also being substantially increased. The research was investigated with the objectives to determine the factors that affect the supply of wheat in Pakistan, and to estimate the short run wheat elasticity's of wheat in Pakistan.

\section{Model Description}

Let q1.......qn be the quantities consumed of $\eta$ goods and be the corresponding

Let $\mathrm{p} 1$............pn be the corresponding price of Wheat

Then $\mathrm{M}=\Sigma \mathrm{n} / \mathrm{I}=1$ pi qi is the total expenditure, which we will refer to as income for short. The consumer chooses the quantity vector q= (qi) to Sogatmize the utility function u (q, subject to the utility Sogatmization $\mathrm{U}$ $=\mathrm{p} . \mathrm{q}$, where $\mathrm{p}=(\mathrm{Pi})$ is the vector of price. The solution to this problem leads to a Marshallian demand equation for good i:

We draw on Clements and Selvaathan (1994) and E.A. slevanuthan and Clements (1995).

$\mathrm{q}_{\mathrm{i}}=\mathrm{q}_{\mathrm{i}}\left(\mathrm{M}, \mathrm{P}_{\mathrm{t}} \ldots \ldots . . \mathrm{P}_{\mathrm{n}}\right)$

To be more concrete. Suppose that (2.1) is logline:

$\log \mathrm{q}_{\mathrm{i}}=\alpha_{\mathrm{I}}+\eta_{\mathrm{I}} \log \mathrm{M}+\sum \eta_{\mathrm{ij}} \log \mathrm{p}_{\mathrm{j}}(2.2) \mathrm{J}=1$

Where $a i$ is and intercept; $\mathrm{n}$ is the $\mathrm{t} 1 \mathrm{~h}$ income elasticity: and nij is the (ij) is the uncompensated price elasticity. The marshallian or money income constant demand equation can be transform into its Slutsky or real income constant counterpart by using the Slutsky decomposition for the uncompensated price elasticity $n i j=n i j-w j n j$. Where nij is the (ij) the compensated price elasticity and $w j=$ piqj $1 M$ is the budget share of good $\mathrm{j}$.the proportion of income spent on $\mathrm{j}$. This yields, after a little algebra the Slutsky demand equation for good $\mathrm{i}: \mathrm{n}$

$\log q_{i}=\alpha_{I}+\eta_{I} \log Q+\sum \eta_{i j} \log p_{j}(2.2) J=1$

Where $\log$ Q- $\log \mathrm{M}-\log \mathrm{P}$, with $\log \mathrm{P}=\sum \eta_{\mathrm{ij}} \log \mathrm{p}_{\mathrm{j}}$ the Division price index , That is $\log \mathrm{Q}$ is money income deflated by the price index . ora measure of the consumer's real income .Note that real income tend the compensated price elasticity's nij appear on the right-hand side of (2.3) while money income and the uncompensated elasticity's nij are in (2.2) .The consumer's Sogatmization problem implies three testable constraint on the demand equations. The first is demand homogeneity which stated that an equi- proportional change in prices has no effect on the quantities demanded when real income is held constant .On the $13^{\text {th }}$ of February, 2008 when decimal currency was introduced into Pakistan, all price and money income doubled overnight: demand homogeneity assure us that this change in the unit of account would have had no effect on 
consumption In the context of equation (2.3) for I= 1, n good, homogeneity is elasticity's for each good being zero.

$$
\sum \eta_{\mathrm{ij}}=0 \quad \mathrm{j}=1 \mathrm{I}-1, \ldots \ldots \ldots . \mathrm{n}
$$

The second constraint is symmetry of the substitution effects or Slutsky symmery .This states that when real income is held constant the effect of a $\$ 1$ ries in the price of one K.G of Wheat, consumptions is exactly equal to the effect consumption on a $\$ 1$ rise in the price one K.G of a wheat to equation (2.3), $\mathrm{n}$ ij is the corresponding slop Symmetry states that this slop is the same when we interchange the $\mathrm{i}$ and $\mathrm{j}$ subscripts, (qi1 pj) nij is the corresponding slope Symmetry states that this slope is the same when we interchange the I and $\mathrm{j}$ subscripts.(qi 1 pj) $\eta \mathrm{ij}=($ aj1 pi) $\eta \mathrm{ji}$

Or multiplying both sides by pi pj $1 \mathrm{M}$

$$
\text { Wi } \eta \mathrm{ij}=\text { wj } \eta \mathrm{ji} \quad \mathrm{i} . \mathrm{j}=1 \ldots \mathrm{n}
$$

Early tests of homogeneity and symmetry by Barten.Byron and other (see Barten, 1977, for references used F-test to test constraints (2.4) and (2.5) and variation thereof. As these hypotheses seemed to be plausible to most it came as a major surprise that many or the early tests led to rejection. What exactly was the problem should the theory of the utility Sogatmizing consumer really be abandoned as advocated by those who took the results literally such as Christenson et at (1975)? Or was the source of the problem the lack of dynamics or other variables excluded from the demand equations?

This and his students finally resolved this puzzle. Using Monte Carlo simulation experiments, they showed convincingly that the rejection were just and artefact of the tests employed . The test statistics have an asymptotic justification, but with sample sized (n, the number of commodities distinguished typically used the tests are seriously biased against the null.i.e... They over-reject. When appropriate adjustments are made to the test statistics, their finite-sample performance for homogeneity and symmetry is performance for homogeneity and symmetry is perfectly satisfactory .For details see Laitinen (1978), Mesiner (1979) the Theil (1987). The third constraint is the law of demand, Viz that demand curves slope down when real income remains constraint. This is sometime referred to as the negativity condition, as the $\mathrm{n} x \mathrm{n}$ matrix of compensated price elasticity's [ $\eta \mathrm{ij}]$, although there are more sophisticated approaches (see ,e.g.. Barten and Geyskens, 1975).

A further set of constraints on the system of $\mathrm{n}$ demand equation is the adding up restrictions, which are implied by the budget constraint. In terms of (2.3), these take the form. $n$

$$
\begin{gathered}
\sum \text { wi } \eta \mathrm{i}=1, \eta \sum \text { wi } \alpha \mathrm{I}=0, \mathrm{j}=1 \ldots \mathrm{n} \\
\mathrm{I}=\mathrm{j} \quad \mathrm{i}=1
\end{gathered}
$$

As the data used to estimate demand equations are constructed to satisfy the budget constraint, these restrictions are not testable.

\section{The Structure of Preferences}

Consider demand equation (2.3) for $\mathrm{I}=1 \ldots \ldots, \mathrm{n}$ goods. In this system of $\mathrm{n}$ equation there are $\mathrm{n}$ intercepts, $\alpha 1 \ldots \ldots \alpha, n$ income elasticities $\eta 1, \eta N$, and $\eta 2$ price elasticities coefficients is $n+n+n 2=n(2+n)$. For a moderate-sized system of $\eta=10$ goods, this total equals 120 which is an impossibly large number of coefficients is still of the order $\eta 2$. One way of proceeding is to set to zero some of the cross-price elasticity's ( $\eta \mathrm{ij}$ for $\mathrm{I} \# \mathrm{j}$ ) in equation (2.3),perhaps on the basis of the intrinsic nature of the commodities involved or on the basic of prior evidence a more systematic approach is to pattern the $\eta \mathrm{x} \eta$ elasticity matrix [ $\eta \mathrm{ij}]$ by further structuring the nature of the consumer's utility function u (q1,......qi).Important early contributions in this area include Barten and Turnover sky (1968) .Leontief (1947),Pearce (1961), 1964), Soon (1961) and Struts (1957). Suppose the $\eta$ goods are broad aggregates such as food, clothing, housing and so on. It is then not unreasonable to view the demand for each good as representing the TJ-83re for some characteristic (s) unique to each good: food provides nutrition and taste, cloting warmth and style and housing provides shelter. These unique or basic characteristics represent fundamental TJ-83res which generate utility. Moreover for them to be truly basic characteristics, it should be the case that there is little or no interaction between tem in the utility function, so that utility is generated by the consumption of food and clotting and housing, with the emphasis on the ands representing the notion of additively. Thesis ideas can be formalized by an additive utility function; whereby utility is the sum or $\mathrm{n}$ sub utility function, one for each good. 


$$
\begin{gathered}
\mu(\mathrm{q} 1, \ldots \ldots . \mathrm{qn})=\sum \quad \mu \mathrm{i}(\mathrm{qi}) \\
\mathrm{I}=1
\end{gathered}
$$

Where ui (qi) is the sub-utiiliy funcation for good I according to (3.1), each marginal utility is a function only of the good in question. and is independent of the consumption of all other good, According to (3.1) is also know as preference independence (P1). An example of (3.1) is the cobb-Douglas utility function, $\mathrm{II}^{\mathrm{n}}{ }_{\mathrm{i}=\mathrm{qj}}$. As monotonic transformations of the utility function leave the demand equations unaffected, we can express the Cobb doglas in logarithmic.

Which is now additive in $\log q 1 \ldots . .$. Log qi

To analyze the implication of PI, let o ij be the Kronecker delta

$\eta \mathrm{Ij}=\Phi \eta(\delta \mathrm{ij}-\mathrm{wj} \eta \mathrm{j})$,

Otherwise and $\Phi$ as the income flexibility .If preferences are of the form (3.1), the (I, j) Th price elasticity then becomes (see, e.g ...Clements et al .., 1995):

Where $\eta \mathrm{I}$ is itch income elasticity and $w \mathrm{j}$ is the budget share of $\mathrm{j}$, as before as

$\eta j=($ qi. $1 ð \mathrm{M})(\mathrm{M} 1 \mathrm{q})$

It follows that the term

Qi $\eta j$ on the right hand side of (3.2) equals

$\Phi \mathrm{j}$ answers the question, how much of a \$1-rise in income is spent on good $\mathrm{j}$ ? The marginal share is to be contrasted with the budget share $w \mathrm{j}=\mathrm{pj}, 1 \mathrm{M}$, which related to

Per-existing, or average, expenditure on $\mathrm{j}$.the ration of the marginal share to the corresponding budget share is the income elasticity, $\eta \mathrm{j}=\theta \mathrm{j} / \mathrm{wj}$

If we use (3.2) in the demand equation (2.3) the substitution term then becomes

$\mathrm{n}$

$\sum \eta \mathrm{ij} \log \mathrm{Pj}=\Phi \eta \mathrm{I}\left(\log \mathrm{Pi}-\log \mathrm{p}^{\prime}\right)$

$\mathrm{j}=1$

n

Where $\log \mathrm{P}=\sum \quad \theta \mathrm{i} \log$ pis the Frisch price

$\mathrm{I}=1$

Index. In contrast with the Division price index which uses marginal shares as weights .As luxuries [ $\eta>1]$ have marginal shares in excess of their budget shares it follows that these goods are more heavily weighted in the Frisch index than in the Division Index. Using (3.3) in (2.3), the itch demand equation under preference independence takes form This shows that PI implies that only the own -relative price appears in each demand equation and that the own price elastic so $\Phi \eta \mathrm{i})$ are proportional to the corresponding income elasticity ( $\eta \mathrm{i})$, with the income flexibility $(\Phi)$ the marginal utility of income respectively .If $\mathrm{C}, \mathrm{F}$ and $\mathrm{U}$ are the compensated, Frisch and uncompensated elasticity's then under PI the relationship between them is

$\mathrm{C}=\mathrm{F}(1-\theta \mathrm{i}) \quad \mathrm{U}=\mathrm{C}-\theta \mathrm{i}$

Where $\theta \mathrm{i}$ is the marginal share of goodi. As all goods are normal under PI, $\theta \mathrm{i}>0$ and it follows that IUI $>$ ICI, It also follows that if the marginal share is small $\mathrm{C} \approx \mathrm{F} \approx \mathrm{U}$. Similar considerations also apply to the cross price elasticity's. The final feature FO preference independence to note is the reduction in the number of unknown parameters in the demand equation. As stated above in the underrated demand equation (2.3) for $\mathrm{I}=1, \mathrm{n}$ there is only one free parameter in the subsection loam, the income flexibility $\Phi$.

The hypothesis of PI can be tested by comparing the fit of the restricted and unrestricted demand equations, equation (3.4) and (2.3) for $\mathrm{I}=1 \ldots \mathrm{n}$ or variants thereof. Most of the implication of PI rejected the rest ion see Barten 1977 for a survey in a highly influential paper. Deaion (1974) analyzed the impaction of PI indirectly by testing whether unrestricted own price elasticity's are proportion to the corresponding income elastic ties Using PAKISTAN data for $n=37$ and 89 commodities he finds no relationship between income and price elasticity's and concludes.

That the assumption of additive preferences is almost certain to be invalid in practice and the use for demand models based on such an assumption will lead to severe distortion of measurement. 
The earlier tests of PI all had only an asymptotic justification, and in view of the difficulties with the asymptotic test of homogeneity and symmetry discussed above in Section II, there is reason to believe that theses test also have is reason to believe that these tests also have problems of over rejecion.S.Selvananthan $(1987,1993)$ develop a Monte Carlo test of PI which avoid possible problems associated with asymptotic and finds a good deal of support for the hypothesis with data from 18 OECD countries S.Selvanathan (1993) also estimates double-log demand equation for $\mathrm{n}=10$ goods in each or 18 OECD countries,. Theses equations have income and the own relative prices on the right hand side but the price elasticity's are otherwise unconstrained .Table 1 (from Clements and S.Sellvanstrained 1994) and Figure 1 present the joint frequency distribution of the $10 \times 18=180$ elasticity's (this only the approximate number as there are minor differences in the number for goods in different countries.

$<$ Insert Table 1 here $>$

Luxuries are indeed more price elastic than necessities, which support the PI hypotheses. Accordingly, in light of this more recent evidence, Deaton (1974) may have been premature in rejecting preference independence.

A wwker version of prefeenc independence is block independence were by the consumer's utility function is additive in groups of gods, rather than individual goods. written S1, SG such that each good belong to only one groups then preferences are of the block independence form when the utility function is the sum of $\mathrm{G}$ group utility function, each involving the quantities of only one group.

$\mathrm{G}$

$\mathrm{U}(\mathrm{q} 1, \mathrm{qn})=\sum \mathrm{ug}(\mathrm{qg}), \quad \mathrm{g}=1$

Where qg is the vector of the qi that fall under Sg Thus if alcohlic beverages make up one block independent group and all other goods another, the marginal utility of, say, Wheat would than be affected by the consumption of Wheat, but not by consumption of any good outside of type group .The demand equation for good.

$\log q \mathrm{t}=\alpha \mathrm{i}+\eta, \log \mathrm{Q}$

$$
\begin{aligned}
& \sum \eta \mathrm{Ij}(\log \mathrm{Pj}-\log \mathrm{P}) \\
& \text { JsubSg }
\end{aligned}
$$

Equation (3.6) is to be compared with (3.4), the corresponding demand equation under preference independence .The assumption of PI implies that only the own price of goods in the dame group as the commodity in question play a role .If the Wheat and the Wheat Floor( Atta) if these form a block independent group then only the prices of the three beverages affect the consumption of each beverages affect the consumption of each beverage and the prices of together goods play no role .It can therefore be seen that there is an appealing unification between preferences an demand equations.

\section{Group Demand and conditional Demand}

Consider gain the demand for Wheat varieties .One way to analyze these beverages would be to postulate that they form a block independent group and then use demand equation. One disadvantage of this approach is that equation group the nose demand equation .One disadvantage of this approach is that equation involves real income and. through their influence on the Frisch price index $\log$ P, the price of other (i.e.. non-Wheat) goods. Conditional demand equations deal only with Wheat and thus avoid the problem. Accordingly a system with a large number of commodities can be transformed into a number of smaller. Independent sub systems, one for each group of goods. In this section, we set out detail of this approach Recall from section II that the budget share WI is the proportion of toil expenditure devoted to good $\mathrm{i}$, while the marginal share

$\theta$ Measures the increase in expenditure on I as a result of a one-dollar increase in income . The budget and marginal shares for the group $\mathrm{Sg}$ are

$$
\begin{aligned}
& \mathrm{Wg}=\sum \mathrm{WI} \quad \theta=\sum \theta \mathrm{i} \\
& \text { JsubSg isubSg }
\end{aligned}
$$

It then follows that $\mathrm{w}^{\prime}=\mathrm{wiWg}$ is the conditional budget share of $\mathrm{i} \theta \mathrm{i}=\theta \mathrm{g}$ is the corresponding conditional marginal share we return to 3.6 the demand equation.

The sum on the left-hand side of equation (4.1) si then just the Division volume index of the group log Qg .If we use the definition of $\theta \mathrm{g}$ and $w i \eta j=\theta g / W g$.

We write the last term on the right hand side of (4.1) is the group income elasticity

$\eta \mathrm{G}=\theta \mathrm{g} / \mathrm{Wg}$ We write the last term on the right hand side of (4.1) as 
$1 \quad \sum \sum$ Wi $\eta \mathrm{ij}(\log \mathrm{Pj}-\log \mathrm{P})$

$\mathrm{W}$

We return to equation (3.6), the double-log demand equation for good me, viz, Sg if we now suppose that the $\mathrm{n}$ goods form only one block in the utility function, then preferences are unrestricted and this summation is over all $n$ goods.

We take infinitesimal of all variables in this equation and then multiply both sides by WI to yield

\section{$\mathrm{N}$}

$$
\text { Wi }(\log \text { qi })=\theta \text { ifd }(\log Q)+\sum \text { vij }\left[\mathrm{d}(\log \mathrm{pj}) \quad \mathrm{J}=1-\mathrm{D}\left(\log \mathrm{P}^{\prime}\right)\right]
$$

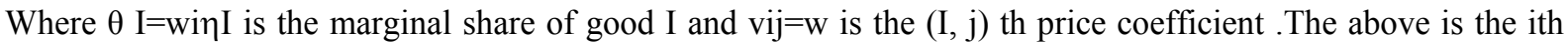
equation of the relative demand system. The variable on the left-hand side or (5.4) has the dual interpretation as the equation of the relative price version of Thiele's (1980a) deferential demand system . The dual interpretation as the quantity component of the change in the budget share of good I and the contribution of I to the Division volume index $d(\log Q)$. Note that the confidents of (5.4), $\theta$ and vim are not necessarily constants.

We define the Slutky coefficient as well as (3.7) in the form.

$\sum=1 \mathrm{vij}=\Phi \theta \mathrm{i}$, we then have

$\mathrm{n}$

Wi d $\left(\log\right.$ qi) $=\theta$ id $(\log Q)+\sum л і$ d $(\log$ pj)

$$
\mathrm{J}=1
$$

Which is the absolute price version of the differential demand equation for good $\mathrm{j}$.the demand equations (5.4) and (5.5) are in terms of infinitesimal changes? The Rotterdam model, due to Barten (1964) and Theil (1965) is a finite-change version of those equations. We write $\mathrm{Dxt}=\log \mathrm{xt}-\log \mathrm{xt}-1$ for the finite $\log$ change in a variable $\mathrm{x}$ from period $t-1$ to $t$ and $w_{i t}$ for the arithmetic average of the budget share wit $=(1 / 2)($ wit + wit- 1$)$ the finite-change version of equation (5.3) si then

$$
\begin{aligned}
& \text { N } \\
& \overline{\mathrm{w}_{\mathrm{it}}} \mathrm{D} \mathrm{q}_{\mathrm{it}}=\theta \mathrm{DQt}+\sum \mathrm{v}_{\mathrm{ij}}\left(\mathrm{Dp}_{\mathrm{jt}}-\mathrm{Dp} \mathrm{p}^{\prime} \mathrm{t}\right) \\
& \mathrm{J}=1 \\
& \mathrm{n} \\
& \overline{\text { wit Dqit }}=\theta D Q t+\sum \text { л ij }\left(D p j t-D p^{\prime} t\right) \\
& \mathrm{J}=1
\end{aligned}
$$

This is the ith demand equation of the absolute price version of the Rotterdam model. Recalling that the Frisch index DP involves the unknown marginal shares equation (5.6) is nonlinear in the parameters, whereas (5.7) is linear .For small values of $\mathrm{n}$, the absolute price version is suitable for estimation but when $\mathrm{n}$ become large it is cumbersome. For large $\mathrm{n}$ it is getter to use the relative price version and impose suitable restrictions on the vim according to notions of separability. A weakness of the Rotterdam model is that both versions have constant marginal shares a defect which is shared with LES as discussed above. It has also been argued that another weakness is that the assumption of consistent coefficients implies that the model is consistent only with CobbDouglas utility. This criticism is originally due to McFadden (1964) but as indicated in the next section more recent research has now established that the model holds under much weaker conditions.

The attraction of AIDS is that it gives an arbitrary first -order approximation to any demand system: satisfies the axioms of choice (almost exactly; aggregates perfectly without invoking the assumption of parallel linter Engle curves: and had a functional form which is consistent with that although many of the TJ-83rable properties of AIDS are possessed by one or other of the Rotterdam or Tran slog models, neither possess all the them simultaneously. The AIDS model in its general form is nonlinear. In practice, however by a suitable approximation to the price index, it is mad liner .As for the Rotterdam and Tran slog models, AIDS can also be used to test the restrictions of homogeneity and symmetry .As Barnett (1984,p 285) says The question therefore naturally arises as to just what has been gained by the wide spared adoption of flexible functional forms, at the expense of linearity, easy satiability, informative parameterization, and well-behaved error structure that has long been available from the older Rotterdam model if flexibility is the answer, then only Monte Carlo studies could confirm the existence of that gain. However, it would be surprising itf the Rotterdam model was to be found to be consistently less flexible than, say the currently fashionable translo model. 
We do not believe that there is a single one-size-fits-all functional form that is ideal for all applicants. Instead, we believe that the characteristics that make a particular functional form suitable for one application my well make it inappropriate for another .For example household budget data typically present the investigator with wide variation in observed level of total less variation in expenditure and more variation in relative prices. Thus it is not surprising that the parametric forms best suited for analyzing household budget data differ from those best suited for analyzing per capita time series data.

\section{Aggregation over Consumers}

The demand equation discussed in the previous section is of micro nature as they are based on the utility-Sogatmizing behavior of the individual consumer. As data in economics are usually available only in aggregate form (e.g... per capita or per adult), it is natural to ask or what extent FO the properties of the micro demand equation carry over to the aggregate (macro) of market demand functions? It can be easily shown that under certain conditions, the micro demand equations. LES given by (5.1), the Tran slog (5.2) and AIDS (5.3) can be aggregated into analogous macro forms; see respectively, Theil (1975/76). Jorgensen et al (1982) and Dalton and Melbourne (1980b) .The aggregation of the differential demand equations (5.4) and (5.5) is more complex .The aggregation issues of the Rotterdam (differential) demand system were considered by Barnett $(1979,1981)$ R.A Selvanathan (1991b) and Tehil $(1971,1975 / 76)$ using the convergence approach .As this is not well understood by many analysis, in this section we briefly outline the convergence approach.

Let us write the micro demand equation

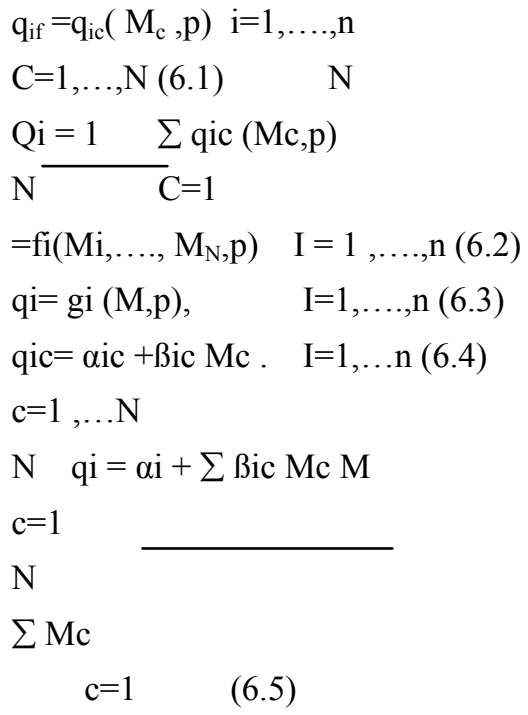

As an approximate linear macro relaion, we apply the Theil's (1971, 1975/76)-convergence approach to aggregation in the following manner. Where we have used plum $\mathrm{N}=0 \mathrm{p}(1)=0$. Thus for sufficiently large $\mathrm{N}(6.5)$ becomes equivalent to (6.6) even when incomes random. Using the above convergence approach, under fairly stung assumptions about the macro parameters and variables, Theil $(1971,1975 / 76)$ shows that (5.4) the micro versions of the differential demand equation in absolute prices, into the corresponding macro equation. E.A Selvanathan (1991b) extends Theil's work by deriving the macro form of the relative price version under the weaker assumptions of Barnett $(1979,1981)$.

\section{Useful Empirical Regularities}

Applied economist need demand elasticity's for trade practices issues, tax analysis, the construction of CGE models and so on .In this section we Present several topic that could be useful in providing guidance for the values of these elasticity's as well as some related issues.

\section{Constructing Price Elastic ties form income Elasticties}

It is usually the case that income elasticites are more redily available that price elasticties income elasticties can some form cross-selection analysis of expender surveys, or from simple judgments about the luxuriousness of goods. Under the assumption of preference independence, as discussed in section III all own and cross price elasticity's can be derived from information regarding the budget share. Income elasticity's and the value of one parameter, the income flexibility .The expression for the $(I, j)$ the price elasticity is given by equation 93.2) which we repeat here for convenience. 
$\eta^{\prime}$ ij $=\Phi \eta I$ (i.j -wj门j), (8.1)

If the income elasticity's and budget share are available, we are still facing with the problem FO what value of $\Phi$ of use in equation (8.1). Frisch (1959) speculated that $\Phi$ would increases in absolute clue) with real income, but the available; e evidence does not indicate strong support fro this income dependence. Clements and S.Selvanthan (1994) present a review of estimates of the income.

$<$ Insert Table 2 here $>$

\section{Wheat Demand}

The demand for Wheat of interest to economists for several reasons. At the individual level, Wheat consumption is subject to great idiosyncratic behavior - some people are like more, some simply takes lot, while others abstain completely. There is thus the intellectual challenge to determine whether this sort of behavior is amenable to conventional economic analysis. Another reason for interest revolves around the public finance aspects of Wheat such as externalities (both positive and negative) and the appropriate levels of taxation. A recent example of the is the controversy generated by the Scales Report (Scales et at. 1995) into Wheat taxation in Pakistan. Finally as in may cases data on Wheat consumption stem from taxation records the quality of the data is above average .It is for these reasons that the Wheat beverages group is perhaps the most studied of all commodity groups, especially in the last 10 years .It is also worth noting that base on our experience, the economics of Wheat consumption make lively teaching material in this sub-section, we st out some key result son Wheat demand which emerge from a number of countries.

Under the assumption of block independence, the composite demand equation for the group $\mathrm{Sg}$ is gives by equation (4.4). Using Pakistani Wheat data. Clemens and S.Selvanatghan (1991) estimate the group income elasticity in the eqution $\eta \mathrm{g}$ to be close to unity.If we set $\eta \mathrm{g}=1$ equation (4.4) can then be written as

$$
\log \mathrm{Qg}-\log \mathrm{Q}=\alpha \mathrm{g}+\Phi\left(\log \mathrm{P}^{\prime} \mathrm{g}-\log \mathrm{P}^{\prime}\right)
$$

Where $\alpha \mathrm{g}$ is an intercept and $\Phi$ are simultaneously the own priced elasticiy of demand for $\mathrm{Sg}$ and the income flexibiliy. E.A. Slevanathan and Clements (1988) use this equation in terns of change to plot the growth in consumption of Wheat as a whole relative to income.$\Delta \log$ p', after replacing the Frisch price indexes (which involve unknown marginal shares) with their Division counterparts (which involve know budget shares): see also clemtns and S.Selvanthan (1991) Figure 2 give gives the plots for Pakistan, the Pakistan and the USA .As can be sen, the three solid lines (the Ls regression lines) are more or less parallel wit ha slope of about $-1 / 2$. Result which is confirmed with more formal methods (see E.A kSelvantathan and Clemsnt 1988) .We speculates elasticity of currently illegal durgs would also be for the odder of $-1 / 2$.

E.A.Selvananthan $(1991$ a) estimates conditional demand equation born Wheat varieties in a number countries .One of his findings is that the three Wheat satisfy the homogeneity and symmetry restrictions, suggesting that drinkers are rational in 4their beverage choice. Selvanathan's conditional income elasticities are given in Table 3. Although there is a good deal of dispersion across countries, it is still the CAS than that elasticity's show a distinct pattern: except for Japan in all counters the conditional income elasticity for Wheat is less than unity. Accordingly, Wheat is a necessity ad sprits a luxury. On the other hand however, there seems to be no particular pattern among the Wheat income elasticity's; and the same is true for the price elasticity's (see E.A.Selvanathan 1991a) for details.

The final empirical regularity pertaining to Wheat consumption is the finding of some complementarily among beverages (see, e.g. Clements and S.Selvanathan 1991). This can be understood in terms of the formal-dinner model in which all three beverages are consumed sequentially, so that one beverage reinforces the utility of the other, rather than being competitive .The BBA model (which john Freebain Attribute to the Tasman Institute) also give rise to the same prediction to complementarily income grows geometrically. Note that the regression line accounts for 84 per cent for the variability for the budget shares, which is impressively high in view of the great difference among the 42 counters with other cross- sectional studies (see Chen 1993, and Theil et al 1989, for reviews a result which leads us to treat the value of this slope as something approaching a natural constant.

The model underlying figure 3 is Working's (1943).

$$
\mathrm{w}=\mathrm{a}+\beta \log \mathrm{M}
$$

$<$ Insert Table 3 here $>$

Thus a doubling of income leads to the food budget share declining by 10 percentage points. (Theil et al 1989) calls this the strong version of Engel's law. This law could be used a short cut in making real-income comparisons. If, for example, the food budget share for some country of group of countries war 10 percentage 
points less than of another, we could then conclude that, primfacie, and the former is twice as affluent as the latter. When the compensated own-price elasticity of demand for food is approximately constant a, corollary of the above law is that a doubling of income leads to the uncompensated own-price elasticity falling in absolute value by 10 (Chen, 1993). This result could be useful when there is little information available about food elasticity's.

\section{Conclusion}

Applied economist need demand elasticity's for trade practices issues, tax analysis, the construction of CGE models and so on .In this section we Present several topic that could be useful in providing guidance for the values of these elasticity's as well as some related issues. Applied demand analysis is usually taken to refer to the micro economic analysis of consumer and producer behavior, especially the nature of input demand and consumer demand equations The demand for Wheat of interest to economists for several reasons. At the individual level, Wheat consumption is subject to great idiosyncratic behavior - some people are like more, some simply takes lot, while others abstain completely. There is thus the intellectual challenge to determine whether this sort of behavior is amenable to conventional economic analysis. Another reason for interest revolves around the public finance aspects of Wheat such as externalities (both positive and negative) and the appropriate levels of taxation.

\section{References}

A. geyskens, E. (1975). The Negativity Condition in Consumer Demand. European Economic Review, 6, 227-7-60.

And Clements, K.W. (1987). Applied demand analysis Results form system wide approaches. Ballinger Cambridge, Massachusetts.

And Turnovsky, SJ. (1966). Some Aspects of the Aggregaion problem for Compostie Demand Equations. International Economic Review, 7, 231-59. http://dx.doi.org/10.2307/2525524

Anton P. Barten. (1977). The Systems of Consumer Demand Functions Approach: A Review. Econometrica, Vol. 45, No. 1, 23-51. http://dx.doi.org/10.2307/1913286

Barnett .W.A. (1979). Theoretical Foundations FAO the Rotterdam Model. Review of Economic Studies, 146, 109-30. http://dx.doi.org/10.2307/2297176

Barten, A.P. (1964). Consumer Demand Functions under Conditions of Almost additive preferences. Econometrica, 32, 1-38. http://dx.doi.org/10.2307/1913731

Bewley, R.A (1986). Allocation Models, Specification Estimation and Applicatns. Ballinger Cambridge Massachusets.

Blundell, R. (1988). Consumver Behabvious, Theroyu and Empirial Evidence -A survey. Economic Journal, 98, 16 -65. http://dx.doi.org/10.2307/2233510

Brown, M.G \& Lee J, Y. (1993). Alternative Specifications of advertising in the Rotterdam Model. European Review of Agricultural Economics, 20, 419-36. http://dx.doi.org/10.1093/erae/20.4.419

Chen, D.L. (1993). world Consumption economic PhD thesis, Economic Research Center, Department for Economics, University of Western Pakistan.

Christensen, L.R, Jorgenson D.W \& lau L.J. (1975). Transcrendental Logarithmic Utility Functions. American Economic Review, 65, 367-83.

Clements. K.W \& Selvanathan, S. (1991). The Economic Determinates of Wheat Consumption. Pakistan Journal of Agricultural Economics, 35, 209-31.

Deffy, M. (1991a). Advertising in Demand systems Testing the Glabraithnin Hypoothesis. Applied economies, 23, 485-96. http://dx.doi.org/10.1080/00036849100000024

Duffy, M. (1991). Advertising and the consumption of tobacco and alcoholic drink: a system-wide analysis. Scottish Journal of Political Economy, 38, 369-86. http://dx.doi.org/10.1111/j.1467-9485.1991.tb00325.x

Frisch. (1959). A completed Scheme for Computing all Direct and Cross Demand Elasticity in a Model with Many Sectors. Econometrica, 27, 177-96.

Goldman, S. M. \& Uzawa H. (1964). A Note on Separability in Demand Analysis. Ecnomietrica, 32, 387-98.

Gorman. W. M. (1959). Separable Utility and Aggregation. Econometrica, 27, 469-81. http://dx.doi.org/10.2307/1909472 
Houthakker, H.S. (1960). Additive Preferences. Econometica, 28.244- 57.

Jorgenson, D.W., L.J. Lau \& T.M. Stoker. (1982). The transcendental logarithmic model of aggregate consumer behavior, in: R. Basman and G. Rhodes, eds., Advances in econometrics. JAI Press, Greenwich, CT.

Laitinen. K. (1978). Why is Demand Homogeneity so often Rejected. Economics Letters, 1, 187-91. http://dx.doi.org/10.1016/0165-1765(78)90022-8

Leontief.W. (1947). Introductions to a theory of the internal Structure of Functional Relationships. Econometidca, 15, 361-73. http://dx.doi.org/10.2307/1905335

Lluch, C. Powell, A.A \& Williams R.A. (1977). Patterns in Household demand and saving oxford.

McFadden D. (1979). The sad fated of the Asymptotic slusky symmetry test for large systems. Economic Letter, 2, 231-33. http://dx.doi.org/10.1016/0165-1765(79)90027-2

Scales, B., Croser .B \& Freebarn, J. (1995). Wheat production in Pakistan AGPS. Canberra.

Selvaathan. S. (1987). Monte Carlo Test of Preference Independence. Economics Letters, 25, 259-61. http://dx.doi.org/10.1016/0165-1765(87)90224-2

Selvananthan, E.A. (1989). Advertising and consumer Demand: A Differential Approach. Economics Letter, 31, 215-19. http://dx.doi.org/10.1016/0165-1765(89)90002-5

Selvanathan S. (1993). A system Wide analysis of international Consumption Patterns. Lower Academic, Dordrech Boston London. http://dx.doi.org/10.1007/978-94-011-1968-9

Sono, M. (1961). The Effect of price change on demand supply of separable goods. International Consumption patterns, Klwer academic. Dordrecthi/ Boston /London.

Stone .T. (1954). Linter Expenditure system and demand analysis .an applicant to the patterns of Birtish demand. Economic Journal, 64, 511-27. http://dx.doi.org/10.2307/2227743

William A. Barnett. (1981). Consumer Demand and Labour Supply. North Holland, Amsterdam.

William Arnold Barnett. (1984). On the flexibility of the Rotterdam model: A first empirical look. European Economic Review, 24, 285-289. http://dx.doi.org/10.1016/0014-2921(84)90057-6

Working H. (1943). Statistical Laws of Family Expenditure. Journal of the American Statistical Association, 38, 453-455. http://dx.doi.org/10.2307/2279311

Table 1. Joint Frequency Distribution of income and Prices Elasticity's (Percentages)

\begin{tabular}{|c|c|c|c|}
\hline \multicolumn{2}{|c|}{ Income elasticity } & \multicolumn{2}{|c|}{ Absolute value of price ela sticity } \\
\hline & $\leq 1 / 2$ & $>1 / 2$ & Total \\
\hline$\leq 1$ & 34 & 21 & 55 \\
\hline$>1$ & 15 & 30 & 45 \\
\hline Total & 49 & 51 & 100 \\
\hline
\end{tabular}


Table 2. Conditional Demand Elasticities for Different Wheat varieties in Pakistan Conditional income Conditional Compensated Conditional advert

(1) Elasticity Price elasticity's tiding el asticity's

(2) TJ -83

Sogat

Pice

(3) (4) (5) (6)

$\begin{array}{lllll}\text { TJ-83 } & .45 & -.17 & .09 & .08 \\ \text { Kiran } & 1.90 & .41 & -.28 & -.13 \\ \text { Sogat } & 1.72 & .16 & -.06 & -.10\end{array}$

$\begin{array}{llll}.08 & .09 & -.05 & -.04 \\ -.13 & -.22 & .15 & .07 \\ -.10 & -.09 & .03 & .05\end{array}$

Table 3. Conditional income Elasticity's for Different varieties of Wheat

\begin{tabular}{|c|c|c|c|c|}
\hline \multirow[b]{3}{*}{ Provinces } & \multirow[b]{3}{*}{ Sample period } & \multirow{2}{*}{\multicolumn{3}{|c|}{$\begin{array}{c}\text { Conditional } \\
\text { In come elasticity's }\end{array}$}} \\
\hline & & & & \\
\hline & & $\mathrm{TJ}-83$ & Sogat & Kiran \\
\hline 1) Sindh & $1995-08$ & .8 & .7 & 1.9 \\
\hline 2) Punjab & 1995-08 & .7 & 1.0 & 1.3 \\
\hline 3) N.W.F.P & 1995-08 & .4 & 1.6 & 1.3 \\
\hline 4) Balouchistan & 1995-08 & & & \\
\hline
\end{tabular}

